\title{
False Beliefs Can Shape Current Consumption
}

\author{
Antonia Mantonakis ${ }^{1}$, Amanda Wudarzewski ${ }^{2}$, Daniel M. Bernstein ${ }^{3}$, \\ Seema L. Clifasefi ${ }^{4}$, Elizabeth F. Loftus ${ }^{5}$ \\ ${ }^{1}$ Department of Marketing, International Business and Strategy, Goodman School of Business, \\ Brock University, St. Catharines, Canada \\ ${ }^{2}$ Department of Psychology, University of Waterloo, Waterloo, Canada \\ ${ }^{3}$ Department of Psychology, Kwantlen Polytechnic University, Surrey, Canada \\ ${ }^{4}$ Center for the Study of Health and Risk Behavior, University of Washington, Seattle, USA \\ ${ }^{5}$ Psychology \& Social Behavior, Criminology, Law \& Society, Cognitive Sciences, University of California, \\ Irvine, USA \\ Email: amantonakis@brocku.ca
}

Received December $21^{\text {st }}, 2102$; revised January $17^{\text {th }}, 2013$; accepted February $15^{\text {th }}, 2013$

\begin{abstract}
In this study, we explore whether false beliefs about a past experience affect current consumption of wine by suggesting to participants that they either "Loved" or "Got Sick" from drinking white wine before age 20. Specifically, we report the consequences of false beliefs about wine, which could take the form of either increased or decreased wine consumption. In response to the suggestion, and similar to other false memory studies many participants became more confident that the suggested event occurred in their past. However, it was easier to influence participants' consumption behavior when we used the "Loved" suggestion rather than the "Got Sick" suggestion. This finding has implications for marketers who use suggestions to influence product consumption by connecting consumers to their autobiographical memories.
\end{abstract}

Keywords: Consumption; False Memory; False Beliefs; Nostalgia; Consumer Memory

\section{Introduction}

Marketers alter extrinsic properties of goods, while leaving their intrinsic qualities untouched. Such extrinsic properties include a good's price (Plassman, O'Doherty, Shiv, \& Rangel, 2008), color (Hoegg \& Alba, 2007), brand name (Allison \& Uhl, 1964), stated ingredients (Lee, Frederick, \& Ariely, 2006), or description (e.g., "healthy" is rated as less tasty; Raghunathan, Naylor, \& Hoyer, 2006). Consumers use extrinsic cues to infer a product's quality, and this can change consumption patterns. Thus, determining the influence of marketing actions on how much a consumer actually consumes is valuable to a firm.

A less studied example of marketing tactics involves using subtle suggestions to change people's beliefs about their autobiographical history with a particular product. In fact, there is a type of advertising used by marketers that capitalizes on consumer nostalgia (Baumgartner, Sujan, \& Bettman, 1992). Nostalgia is a warm, longing feeling from the past that can influence consumer preferences (Holbrook, 1993; Holbrook \& Schindler, 2003). For example, Kellogg's popular jingle, "Two scoops of juicy raisins in Kellogg's Raisin Bran" was revived in 2006, 13 years after it originally aired. We wondered whether making subtle suggestions pertaining to consumers' autobiographical history (e.g., having loved a specific good in the past) would increase their consumption of the referenced good.

There is ample evidence that (false) advertising messages received after a consumption experience can alter how that experience is remembered and evaluated (Braun, 1999; Braun, Ellis, \& Loftus, 2001; Cowley \& Janus, 2004). We know that simply asking a question increases the frequency of behavior pertaining to that question. For example, asking one's opinions about voting increases the likelihood that they will vote (Kraut
\& McConahay, 1973). However, we do not know whether false messages (i.e., asking a question about something that never happened) affect consumption. Specifically, we do not know whether marketing-related suggestions or questions about a person's autobiographical history can change consumption patterns.

Although marketers would not likely use nostalgia to decrease consumption, it seems that subtle, negative suggestions about a person's autobiographical history can decrease consumption. Several studies demonstrate that false beliefs, created by convincing people that they had a negative experience with a food as a child (which never actually happened), can make people report avoidance of the food, and actually eat less of it (Bernstein, Laney, Morris, \& Loftus, 2005; Geraerts, Bernstein, Merckelbach, Linders, Raymaekers, \& Loftus, 2008; Scoboria, Mazzoni, \& Jarry, 2008; Scoboria, Mazzoni, Jarry, \& Bernstein, 2012; see also Morewedge, Huh, \& Vosgerau, 2010). The current study extends the previous literature by directly addressing whether false suggestions can affect subsequent consumption patterns. Additionally, it is not clear from the previous studies in this area: a) whether subtle false suggestions about a person's more recent (as opposed to childhood) autobiographical history can change consumption; b) whether subtle false suggestions can increase consumption; and c) whether it might be easier for false suggestions to increase rather than decrease consumption. Our study directly speaks to these shortcomings.

In the study we present here, we examine whether a false suggestion that participants had experienced either a positive or a negative experience with white wine prior to age 20 influenced their actual consumption. Specifically, we explore whether a false belief of having loved or gotten sick from drinking white wine prior to the age of 20 would result in increased or 
decreased white wine consumption, respectively.

How would a false belief change consumption? Autobiographical memory is a consumer's memory of their own personal past experiences. This type of memory is of interest to consumer behavior researchers because, though malleable, memory relates to the development of a person's self-concept (Hyman, Husband, \& Billings, 1995). The broad theoretical framework from which this type of research stems is the notion of reconstructive memory, or the notion that memory is not about simple retrieval, but rather reconstruction (Bartlett, 1932). Indeed consumers' unique autobiographical memories are continuously being revised to fit changing knowledge about the self (Neisser \& Fivush, 1994). Researchers attempt to plant product-related memories about experiences, and subsequently examine whether these planted memories affect participants' confidence ratings of actually having had those experiences in the past (Braun et al., 2001). Simply imagining an experience is sufficient to increase confidence that the experience occurred to oneself (Garry, Manning, Loftus, \& Sherman, 1996), leading to a false autobiographical belief.

Given the aforementioned work, false suggestions (Loftus \& Pickrell, 1995) and instructions for imagination (Hyman \& Pentland, 1996) can lead to false autobiographical beliefs (as measured by confidence ratings). Several studies show that subtle, negative suggestions about a person's autobiographical history can decrease consumption, but the question remains as to whether subtle, positive suggestions can lead to increases in consumption (but see Laney, Morris, Bernstein, Wakefield, \& Loftus, 2008 for one example done with self-reported food preferences). The current research examines whether there are similar effects of positive versus negative false autobiographical suggestion on actual consumption.

One study reports that true memories for positive and negative experiences serve different functions (Pillemer, 2009), and that true autobiographical memories influence intentions and behavioral outcomes more so for positive versus negative autobiographical memories (Kuwabara \& Pillemer, 2010). Specifically, while recounting true positive memories increases intentions and increases the likelihood of executing those intentions (see also Pezdek \& Salim, 2011), recounting true negative memories has no such effect. Based on this finding, we hypothesized that subtle false suggestions relating to one's autobiographical history will be more likely to lead to behavioral consequences for positive suggestions compared to negative suggestions.

\section{Method}

\section{Participants}

We recruited 181 students and local community members of a mid-sized North American university via advertisements to participate in a study of "Tastes and Experiences". Our sample was $63 \%$ female and $37 \%$ male, ranging in age from 19 , the local legal drinking age, to 77, with an average age of 24.6, and a median of 22. Participants received either course credit or $\$ 10$ as compensation. The University's Institutional Review Board approved all experimental methods.

\section{Experimental Groups}

We randomly assigned participants to one of two groups, which differed based on the valence of the critical item ("Loved to drink white wine" or "Got sick after drinking white wine"). Within each of these two groups, we further randomized participants into either the experimental or control condition, based on whether a wine suggestion would be received during a second experimental session. Thus, there were two control groups; one corresponding to the "Loved" group and one corresponding to the "Got Sick" group (cf. Bernstein et al., 2005).

\section{Procedure}

Participants completed two sessions wherein they completed various questionnaires. During session 1, participants individually completed questionnaires, including a Party Behavior Questionnaire, Food Preferences Questionnaire, and a 24-item Food History Inventory (Bernstein et al., 2005). The Food History Inventory contained one of two critical events: "Loved to drink white wine" $(\mathrm{n}=87)$ or "Got sick after drinking white wine" $(\mathrm{n}=94)$. Given that "Got Sick" was used in previous research (Bernstein et al., 2005), and there is no direct opposite of it, we chose to use "Loved", another manipulation used in previous research (Laney, Kaasa, Morris, Berkowitz, Bernstein, \& Loftus, 2008). Participants rated whether each of the 24 events (e.g., "Ate a piece of banana cream pie") on the Inventory occurred to them before the age of 20 , using a scale anchored at $1=$ definitely did not happen and $8=$ definitely did happen.

One week later, during session 2, participants returned to the lab and received false feedback about their responses to the questionnaires that they had completed in session 1 . The experimenter falsely suggested to all participants that, after running their previous responses through a computer system, the system had generated an individualized profile of their consumption experiences prior to age 20. Each participant's profile indicated that they liked pizza and that they disliked spinach. Additionally, most participants received a) a further false suggestion about the white wine event to which they had responded in the first session ("You loved drinking white wine" for the "Loved" group, or "You got sick after drinking white wine" for the "Got Sick" group); the remaining participants received b) no false suggestion about wine. This produced four groups: the Loved/Suggestion group $(\mathrm{n}=61)$, the Loved/No Suggestion group $(n=26)$, the Got Sick/Suggestion group $(n=58)$, or the Got Sick/No Suggestion group $(\mathrm{n}=36)$. To ensure that participants considered the feedback, the experimenter instructed them to imagine the setting in which these experiences may have happened, and indicate where the event may have occurred, and with whom they may have been when it occurred.

Participants individually completed another questionnaire similar to those used in session 1 (i.e., a Food Costs Questionnaire where participants were asked the most they'd be willing to pay for items such as a dozen eggs; Bernstein et al., 2005), as well as the Food History Inventory (again). Responses on the critical question in the Food History Inventory were used to determine whether there were any changes in confidence that the critical event ("Loved to drink white wine" for the Loved/ Suggestion and Loved/No Suggestion groups; "Got sick after drinking white wine" for the Got Sick/Suggestion and Got Sick/No Suggestion groups) occurred before age 20. Note that random fluctuation in responses to the critical event would have been captured in the No Suggestion conditions. Participants also completed a memory-or-belief form where they answered questions about their memory for the events mentioned in the 
generated profile. Participants indicated " $M$ " if they had a "memory" about the event, a "B" if they had a "belief that the event happened to them but could not generate a memory", and "P" if they were "positive that the events on the generated profile did not happen to them before the age of 20". Participants elaborated on their answers by writing as many details as possible, or by writing why they were certain the event never happened.

After participants answered various demographic questions and a question about what they thought the study's purpose was, we offered them a complimentary glass of white wine (3.04 ounces; $90 \mathrm{ml}$ in total, which is less than a standard alcoholic drink; MADD, n.d.), which we ostensibly offered to mark the grand opening of a new wine institute at the University. We chose wine as our alcoholic beverage because a new Oenology and Viticulture Institute did in fact open in our University, and we had access to student-produced wine, which could be used in behavioral studies. Participants could drink as much or as little from the glass (to the maximum of 3.04 ounces; $90 \mathrm{ml}$ in total) as they liked. After the session, the experimenter measured in $\mathrm{ml}$ the amount of wine consumed. Participants were debriefed, and were administered a breathalyzer test prior to departing the lab, to ensure that blood alcohol levels were below the legal limit of .08 for driving We randomly assigned participants to one of two groups, which differed based on the valence of the critical item ("Loved to drink white wine" or "Got sick after drinking white wine"). Within each of these two groups, we further randomized participants into either the experimental or control condition, based on whether a wine suggestion would be received during a second experimental session. Thus, there were two control groups; one corresponding to the "Loved" group and one corresponding to the "Got Sick" group (cf. Bernstein et al., 2005).

\section{Results}

We wanted to focus on examining the effects of changes in beliefs (from the false suggestion) on consumption, so we analyzed responses to only the questionnaire pertaining to changes in belief. Confidence ratings for the critical items from the Food History Inventory, as well as the amount consumed, represent our key dependent variables of interest, and we analyze these in turn.

We classified participants as having arguably true memories of the critical event if they had scored above 4 for the critical item on the Food History Inventory during session 1, and also reported a memory or belief of the experience (Geraerts et al., 2008). Exclusion criteria included participants who we classified as having arguably true memories of the event $(n=54)$ or those who correctly guessed the hypothesis of the study $(n=5)$. Including these 59 participants did not change the results; however, we wanted to remove them to ensure that we were studying arguably false beliefs and memories. To separate those who did and did not believe the suggestion, we identified participants as being believers $(n=36)$, nonbelievers $(n=43)$, or controls $(n=43)$. We classified participants as believers if they met all of these criteria: 1) low confidence ratings that the critical event occurred before age 20 in session 1 (i.e., they answered 1 - 4 on the Food History Inventory during session 1); 2 ) an increase in confidence ratings from session 1 to session 2 ; and 3) reported the critical event as a "memory" $(n=16 ; 44 \%$ of believers) or "belief" ( $\mathrm{n}=19 ; 53 \%$ of believers) that it occurred, in session 2. We classified participants as nonbelievers if their confidence that the critical event occurred before age 20 did not change or decreased from session 1 to session 2, or if they reported that the event positively did not occur. Thirty-five out of the 43 participants in this category reported that they were positive the event did not occur. We present two primary data analyses to address our research question, one based on changes to confidence after receiving the suggestion, and one based on changes to wine consumption.

\section{Confidence Ratings}

Confidence ratings for session 1 and session 2 on the Food History Inventory appear in Figure 1. We conducted a $2 \times 3$ mixed analysis of variance (ANOVA), with Food History Inventory Session (1 vs. 2 ) as the within-subjects factor and Believer type (believer, nonbeliever, and control) as the between-subjects factor. A significant Food History Inventory session by believer type interaction emerged, $F(2,119)=68.87$, $p<.001, \eta p^{2}=.54$. The interaction remains significant when collapsing Believers and Nonbelievers, and comparing only participants in the Suggestion versus No Suggestion groups in a

Food History Inventory Ratings

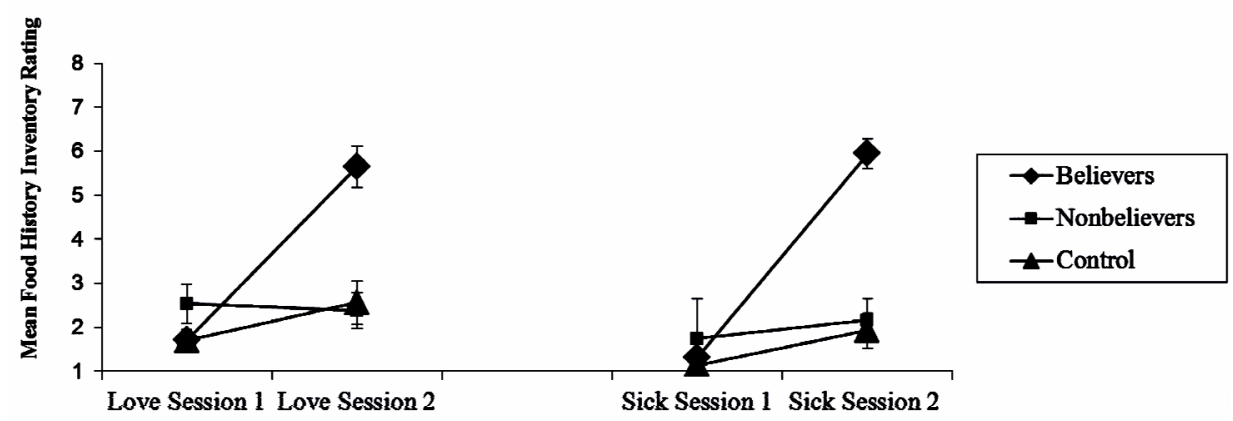

Figure 1.

Participants' mean confidence in the critical event (having loved or having gotten sick from white wine before the age of 20) for session 1 and 2 as a function of experimental condition. Note. Sessions 1 and 2 were separated by 1 week; Session 1 occurred before participants received the false suggestion. Results for participants who believed the false suggestion (Believers), participants who did not believe the false suggestion (Nonbelievers), and control participants who were not exposed to the false suggestion (Controls). Error bars represent standard errors of the means. 
2 (Food History Inventory Session) $\times 2$ (Suggestion type) ANOVA, $F(1,120)=7.79, p=.006, \eta p^{2}=.06$.

As expected by our definition of Believers for the "Loved" group, believers were more confident that the event happened after the manipulation than before, whereas nonbelievers and controls expressed low confidence in both sessions. A $2 \times 3$ ANOVA conducted on the "Loved" group, with Food History Session (1 versus 2) and Believer type (believers, nonbelievers, controls) as factors showed that believers were more confident than nonbelievers and controls that the critical event (having loved drinking white wine) had occurred before age 20, $F(2,51)$ $=32.57, p<.001, \eta p^{2}=.56$. Whereas the believers showed a significant increase in confidence from session 1 to $2, F(1,13)$ $=104.31, p<.001, \eta p^{2}=.89$, this was not the case for the nonbelievers or controls ( $p$ 's $=.46, .11$ respectively). Age did not moderate the effects.

As expected, a $2 \times 3$ ANOVA conducted on the "Got Sick" group, with Food History Session (1 versus 2) and Believer type (believers, nonbelievers, controls) as factors, showed that believers were more confident than nonbelievers and controls that the critical event (having gotten sick from white wine) had occurred before age $20, F(2,65)=35.75, p<.001, \eta p^{2}=.52$. Whereas the believers showed a significant increase in confidence from session 1 to $2, F(1,21)=180.26, p<.001, \eta p^{2}=.90$, this was not the case for the nonbelievers or controls ( $p$ 's $=.32, .06$ respectively). Age did not moderate the effects.

\section{Consumption Data}

In Table 1, we report the amount of wine that participants consumed. A 2 × 3 ANOVA with Valence ("Loved" vs. "Got Sick") and Believer type (believers, nonbelievers, controls) as factors revealed that both "Loved" and "Got Sick" groups differed in the amount of wine that they consumed, based on whether they were believers, nonbelievers, or controls, interaction, $F(2,116)=4.07, p=.02, \eta p^{2}=.07$.

For the "Loved" group, the believers $(M=58.21)$ consumed significantly more than both the "Loved" nonbelievers, $(M=$ 29.92), $F(1,36)=6.84, p=.013, \eta p^{2}=.16$, and the "Loved" controls $(M=23.68), F(1,28)=7.69, p=.01, \eta p^{2}=.22$. Note that when collapsing across Believer type, the effect of Suggestion versus No Suggestion on amount consumed fails to reach conventional levels of statistical significance, $F(1,53)=2.70, p$ $=.11$.

For the sick group, the believers $(M=28.95)$ consumed slightly less than the sick nonbelievers $(M=34.89)$, and the sick controls $(M=33.63)$, although this reduction was not statistically significant for either ( $p$ 's $=.52$ and .59 respectively).

Table 1.

Mean (standard error of the mean in parentheses) amout of wine consumed in $\mathrm{ml}$ and sample size.

\begin{tabular}{ccccc}
\hline Suggestion Condition & \multicolumn{2}{c}{ "Loved" Group } & \multicolumn{2}{c}{ "Got Sick" Group } \\
\hline & $M(S E)$ & $N$ & $M(S E)$ & $N$ \\
Believers & $58.21(9.38)$ & 14 & $28.95(5.27)$ & 22 \\
Nonbelievers & $29.92(6.11)$ & 24 & $34.89(7.79)$ & 19 \\
Controls & $23.68(8.26)$ & 16 & $33.63(6.57)$ & 27
\end{tabular}

Note: Results for participants who believed the false suggestion (Believers), participants who did not believe the false suggestion (Nonbelievers), and control participants who were not exposed to the false suggestion (Controls).
Again, when collapsing across Believer type, the effect of Suggestion vs. No Suggestion on amount consumed is not significant, $F(1,67)<1, p=.91$.

Comparing the "Loved" and "Got Sick" groups within believer type, we find that the "Loved" believers consumed significantly more than the "Got Sick" believers, $F(1,34)=8.64$, $p<.006, \eta p^{2}=.21$. However, the "Loved" and "Got Sick" suggestions do not lead to different consumption patterns for nonbelievers, $F(1,41)<1, p=.62$ or controls, $F(1,41)<1, p$ $=.37$.

\section{Discussion}

In this research study, we examined the effects of false suggestions on confidence ratings and actual consumption by suggesting to participants that they had either "Loved" drinking white wine, or "Got Sick" from white wine, before age 20. Our results indicate that false suggestion about the wine experience creates a belief that the experience occurred. This false belief, in turn, influences behavior (here measured as actual consumption).

Participants who either received a "Loved" or "Got Sick" suggestion were more likely to increase their confidence that the suggested event occurred before age 20, and this depended on whether participants actually believed the suggestion. More importantly, this increased confidence related to changes in consumption for "Loved" believers. That is, participants who believed the "Loved" suggestion consumed significantly more white wine than those who did not believe this suggestion. These findings accord well with a recent meta-analysis of all published studies involving false food memories (Bernstein, Scoboria, \& Arnold, Unpublished data). In that analysis, the authors found that the consequences of false memories and beliefs depend on participants who change their ratings on the Food History Inventory after suggestion. That study also showed that self-reported consequences are greater for "Loved" than for "Got Sick" suggestions.

These current findings make several key contributions to the literature. To our knowledge, this is the first study to show that a false suggestion regarding an adult event produced elevations in confidence similar to previous studies on childhood events. Second, whereas previous researchers have shown that it is possible to change a consumer's evaluation about a product by changing their remembered schema about the product through false suggestions (Braun, 1999), we were able to show that a false suggestion could alter behavior in relation to that product. In other words, through false suggestions, we were able to increase a person's actual product consumption. Third, this is the first study to try to increase or decrease consumption within the same experiment, using the same critical item (white wine). Although previous research demonstrates that people are less likely to consume something associated with a suggestion of having gotten sick from it (Geraerts et al., 2008; Scoboria et al., 2008 ; 2012), here we found that it was easier to influence participants' drinking behavior by suggesting that they had loved rather than gotten sick from drinking white wine previously. For the believers in the "Loved" condition, a false suggestion related to an increase in the amount of white wine consumed relative to the controls in that condition, whereas this result did not occur for the believers in the "Got Sick" condition.

In explaining why the believers in the "Got Sick" condition did not show a significant decrease in the amount of wine con- 
sumed relative to the controls in that condition, we point to a study using a false feedback suggestion with food. The study with food shows that people could be led to believe that they had gotten sick on strawberry ice cream, and subsequently report avoidance of that food. However, the same suggestion does not work with another food-chocolate chip cookies (Bernstein et al., 2005). The authors reported that the cookie suggestion does not increase confidence in the cookie event, nor does it produce avoidance. Therefore, it may be harder to plant false beliefs about frequently consumed foods compared to relatively novel foods (such as strawberry ice cream). To produce avoidance with the more common food, the possibility remains that a stronger manipulation is necessary. The current results indicate that the "sick" suggestion succeeded in increasing confidence that the sick event happened. However, maybe a stronger sick suggestion is needed to reduce consumption. Speculation discussed by Kuwabara and Pillemer (2010) indicates that the negative experiences recounted by study participants may not be salient enough to outweigh the collection of positive experiences in memory.

It is possible that the false suggestion and subsequent belief change may serve as a reminder to participants of other, true past experiences related to the suggestion. However, this pertains to all studies that examine false memory implantation. The very nature of the manipulation (i.e., having participants imagine a prior, false experience) may lead them to recall actual experiences. Future studies may wish to examine the extent to which the manipulation may prompt recall of other, similar experiences, including measurements that track qualitative responses to imagination exercises, to illuminate the role of imagination in creating false beliefs in different subgroups.

One limitation of the current study design is that the "Loved" and "Got Sick" suggestions were not opposites. Perhaps the "Loved" suggestion was more general, which made participants more likely to generate alternative, true memories of the event which then produced increased consumption. Future studies examining both valences could better match the specificity of the suggestion (e.g., "enjoyed" vs. "did not enjoy").

Finally, propensity towards feeling nostalgia (or changes in mood that may result) may be a relevant moderator to our results. These two factors (nostalgia proneness and mood) cannot be ruled out as possible explanations for the effects in the current study. Examining nostalgic tendencies as a moderator may be a fruitful avenue for future research.

What is the mechanism responsible for the effects observed in our study? Processing fluency is the relative ease or difficulty of performing a cognitive activity, and may be attributed to preference, familiarity, and other cognitive judgments (Alter \& Oppenheimer, 2009; Mantonakis, Bernstein, \& Loftus, 2011; Whittlesea, 1993). To illustrate, asking questions may increase the processing fluency of the target (e.g., loving white wine), making cognitions at the time of judgment feel easier to process, which results in changes in behavior (Janiszewski \& Chandon, 2007). Some have argued that the consequences of false beliefs and memories are also due to processing fluency (Bernstein et al., 2005). For example, receiving a false suggestion and imagining that one loved a particular food, such as asparagus, the first time one tried it, is associated with increased belief that this event occurred in the person's past and increased preference for asparagus. This increased belief likely occurs because the false feedback primes participants to process the belief associated with the critical item, asparagus, more fluently in sub- sequent encounters with asparagus. Participants interpret this increased fluency as familiarity, and misattribute the familiarity to prior experience: "I did love asparagus the first time I tried it" and current preference ratings: "I love asparagus now". Similarly, in the present experiment, the suggestion about white wine may increase the fluency with which people process the item, white wine, in subsequent encounters. This increased fluency, in turn, increases the chances that a person will come to believe the false suggestion and alters consumption accordingly (see Bernstein, Pernat, \& Loftus, 2011). Future work should explore the role of processing fluency in the consequences of false beliefs by building into the design of the study measurements of processing fluency.

\section{Practical Applications}

Public policy research seeks to determine how consumers can misinterpret marketing messages, possibly leading to false beliefs about products (Burke, DeSarbo, Oliver, \& Robertson, 1988; Jacoby \& Hoyer, 1982). Consumer beliefs may be especially susceptible to reconstruction in imagery-rich consumer environments, such as web-based communication interfaces between firms and consumers (e.g., blogs; Lakshmanan \& Krishnan, 2009). The current findings apply to this policy issue. Marketers use various methods, including autobiographical referencing, to remind consumers about past experiences. Advertisements for product-related experiences at Disneyland, Swiss Chalet restaurants, and wineries use such methods, and cue consumers to imagine their past experiences associated with the product. Recent research suggests that listening to an imageryevoking radio ad may lead consumers to believe falsely that they had experience with the brand featured in the ad (Rajagopal \& Montgomery, 2011). Our results demonstrate that a) such subtle suggestions create false beliefs in some consumers, and b) there may be behavioral consequences to such false beliefs, which policy makers should consider.

A final point to note is the ethical issue of increasing any behavior, such as drinking alcohol, or any other potentially harmful behavior that a consumer may exhibit, either a) as part of false memory studies or b) as part of advertising and marketing campaigns in general. As for our first point, we fully debrief participants at the end of our studies and make them aware of the false memory literature and the associations between false memories and subsequent behavior. To our knowledge, no one has experienced long term negative consequences as a result of participating in these studies. However, researchers may wish to consider the impact that participation in such studies has on individuals (see Otgaar, Scoboria, \& Smeets, 2012). As for our second point, future research may wish to focus on ways to help consumers overcome such possible behavioral consequences (LaTour \& LaTour, 2010). For starters, perhaps the findings that we report here can be used as an educational tool to equip policy makers and consumers alike regarding certain marketing tactics that may increase potentially harmful behaviors. Indeed, such awareness has already led to certain regulation changes on cigarette advertising that prohibits promotion of a tobacco product if any of its brand elements is displayed on a nontobacco product or is used with a service, if the nontobacco product or service is appealing to young persons or promotes a glamorous lifestyle (Department of Justice, n.d.). Once more work has been done on how behaviors can be manipulated by altering beliefs about consumers' past experi- 
ences, we will need to think about whether such activities will also demand regulation.

\section{Acknowledgements}

The authors thank Joey Hoegg, University of British Columbia, and Reid Hastie, University of Chicago Booth School of Business, for comments on an early version of this manuscript. This research was also supported by an Undergraduate Student Research Award to Amanda Wudarzewski from the Natural Sciences and Engineering Research Council of Canada. Dr. Clifasefi would like to acknowledge the National Institutes of Health/ National Institute on Alcohol and Alcohol Abuse (\#T32 AA07455 and \#F32 AA015240) for partially supporting her time in this research endeavor.

\section{REFERENCES}

Allison, R. I., \& Uhl, K. P. (1964). Influence of beer brand identification on taste perception. Journal of Marketing Research, 1, 36-39. doi: $10.2307 / 3150054$

Alter, A. L., \& Oppenheimer, D. M. (2009). Uniting the tribes of fluency to form a metacognitive nation. Personality and Social Psychology Review, 13, 219-235. doi:10.1177/1088868309341564

Bartlett, F. C. (1932). Remembering: A study in experimental and social psychology. Cambridge: Cambridge University Press.

Baumgartner, H., Sujan, M., \& Bettman, J. R. (1992). Autobiographical memories, affect, and consumer information processing. Journal of Consumer Psychology, 1, 53-82. doi:10.1016/S1057-7408(08)80045-9

Bernstein, D. M., Laney, C., Morris, E. K., \& Loftus, E. F. (2005). False beliefs about fattening foods can have healthy consequences. Proceedings of the National Academy of Sciences of the United States of America, 102, 13724-13731. doi:10.1073/pnas.0504869102

Bernstein, D. M., Pernat, N., \& Loftus, E. F. (2011). The false memory diet: False memories alter food preference. In V. R. Preedy, R. R. Watson, \& C. R. Martin (Eds.), Handbook of behavior, food, and nutrition (pp. 1645-1663). New York: Springer.

Bernstein, D. M., Scoboria, A., \& Arnold, R. (Unpublished data). Belief moderates the path from false memory to behavior.

Braun, K. A. (1999). Post experience advertising effects on consumer memory. The Journal of Consumer Research, 25, 319-334. doi: $10.1086 / 209542$

Braun, K. A., Ellis, R., \& Loftus, E. F. (2001). Make my memory: How advertising can change our memories of the past. Psychology \& Marketing, 19, 1-23. doi:10.1002/mar.1000

Burke, R. R., DeSarbo, W. W., Oliver, R. L., \& Robertson, T. S. (1988). Deception by implication: An experimental investigation. Journal of Consumer Research, 14, 483-494. doi:10.1086/209130

Cowley E., \& Janus, E. (2004). Not necessarily better, but certainly different: A limit to the advertising misinformation effect. Journal of Consumer Research, 31, 229-235. doi:10.1086/383438

Department of Justice (n.d.). Tobacco Act 1997. URL (last checked 19 December 2012). http://laws-lois.justice.gc.ca/PDF/T-11.5.pdf

Garry, M., Manning, C. G., Loftus, E. F., \& Sherman, J. (1996). Imagination inflation: Imagining a childhood event inflates confidence that it occurred. Psychonomic Bulletin \& Review, 3, 208-214. doi: 10.3758/BF03212420

Geraerts, E., Bernstein, D. M., Merckelbach, H., Linders, C., Raymaekers L., \& Loftus, E. F. (2008). Lasting false beliefs and their behavioral consequences. Psychological Science, 19, 749-753. doi:10.1111/j.1467-9280.2008.02151.x

Holbrook, M. B. (1993). Nostalgia and consumption preferences: Some emerging patterns of consumer tastes. Journal of Consumer Research, 20, 245-256. doi:10.1086/209346

Holbrook, M. B., \& Schindler, R. M. (2003). Nostalgic bonding: Exploring the role of nostalgia in the consumption experience. Journal of Consumer Behavior, 3, 107-127. doi:10.1002/cb.127
Hoegg, J., \& Alba, J. W. (2007). Taste perception: More than meets the tongue. Journal of Consumer Research, 33, 490-498. doi.10.1086/510222

Hyman, I. E., Husband, T. H., \& Billings, J. F. (1995). False memories of childhood experiences. Applied Cognitive Psychology, 90, 181197. doi:10.1002/acp.2350090302

Hyman, I. E., \& Pentland, J. (1996). The role of mental imagery in the creation of false childhood memories. Journal of Memory and Language, 35, 101-117. doi:10.1006/jmla.1996.0006

Impaired Driving (n.d.). Fact sheet: Blood alcohol concentration. URL (last checked 19 December 2012)

http://www.mto.gov.on.ca/english/safety/impaired/fact-sheet.shtml\#b ac

Jacoby, J., \& Hoyer, W. D. (1982). Viewer miscomprehension of televised commercials: Selected findings. Journal of Marketing, 46, 1226. doi: $10.2307 / 1251357$

Janiszewski, C., \& Chandon, E. (2007). Transfer appropriate processing, response fluency, and the mere measurement effect. Journal of Marketing Research, 44, 309-323. doi:10.1509/jmkr.44.2.309

Kraut, R. E., \&McConahay, J. B. (1973). How being interviewed af- fects voting: An experiment. The Public Opinion Quarterly, 37, 398406. doi: $10.1086 / 268101$

Kuwabara, K. J., \& Pillemer, D. B. (2010). Memories of past episodes shape current intentions and decisions. Memory, 18, 365-374. doi:10.1080/09658211003670857

Lakshmanan, A., \& Krishnan, H. S. (2009). How does imagery in interactive consumption lead to false memory? A reconstructive memory perspective. Journal of Consumer Psychology, 19, 451-462. doi:10.1016/j.jcps.2009.04.005

Laney, C., Kaasa, S. O., Morris, E. K., Berkowitz, S. R., Bernstein, D. M., \& Loftus, E. F. (2008). The red herring technique: A methodological response to the problem of demand characteristics. Psychological Research, 72, 362-375. doi:10.1007/s00426-007-0122-6

Laney, C., Morris, E. K., Bernstein, D. M., Wakefield, B. M., \& Loftus, E. F. (2008). Asparagus, a love story: Healthier eating could be just a false memory away. Experimental Psychology, 55, 291-300. doi: $10.1027 / 1618-3169.55 .5 .291$

LaTour, K. A., \& LaTour, M. S. (2010). Bridging aficionados' perceptual and conceptual knowledge to enhance how they learn from experience. Journal of Consumer Research, 37, 688-697. doi: $10.1086 / 655014$

Lee, L., Frederick, S., \& Ariely, D. (2006). Try it, you'll like it: The influence of expectation, consumption, and revelation on preferences for beer. Psychological Science, 17, 1054-1058. doi:10.1111/j.1467-9280.2006.01829.x

Loftus, E. F., \& Pickrell, J. E. (1995). The formulation of false memories. Psychiatric Annals, 25, 720-725.

Mantonakis, A., Bernstein, D. M., \& Loftus, E. F. (2011). Attributions of fluency: Familiarity, preference, and the senses. In P. A. Higham, \& J. P. Leboe (Eds.), Constructions of remembering and metacognition: Essays in honor of Bruce Whittlesea (pp. 40-50). Basingstoke: Palgrave MacMillan.

Morewedge, C. K., Huh, Y. E., \& Vosgerau, J. (2010). Thought for food: Imagined consumption reduces actual consumption. Science, 330, 1530-1533. doi:10.1126/science. 1195701

MADD (n.d.).The ABCs of BACs. URL (last checked 19 December 2012).

http://www.madd.ca/media/docs/ABCs\%20_of_BACs_FINALdoc.p df

Neisser, U., \& Fivush, R. (1994). The remembered self: Construction and accuracy in the self narrative. Cambridge: Cambridge University Press. doi.10.1017/CBO9780511752858

Otgaar, H., Scoboria, A., \& Smeets, T. (2012). Experimentally evoking nonbelieved memories for childhood events. Journal of Experimental Psychology: Learning, Memory, \& Cognition, in Press. doi.10.1037/a0029668

Pezdek, K., \& Salim, R. (2011). Physiological, psychological and behavioral consequences of activating autobiographical memories. Journal of Experimental Social Psychology, 47, 1214-1218. doi:10.1016/j.jesp.2011.05.004

Pillemer, D. B. (2009). Twenty years after Baddeley (1988): Is the 


\section{A. MANTONAKIS ET AL.}

study of autobiographical memory fully functional? Applied Cognitive Psychology, 23, 1193-1208. doi:10.1002/acp.1619

Plassman, H., O’Doherty, J. P., Shiv, B., \& Rangel, A. (2008). Marketing actions can modulate neural representations of experienced pleasantness. Proceedings of the National Academy of Sciences of the United States of America, 105, 1050-1054.

doi:10.1073/pnas.0706929105

Raghunathan, R., Naylor, R., \& Hoyer, W. (2006). The unhealthy = tasty intuition and its effects on taste inferences, enjoyment, and choice of food products. Journal of Marketing, 70, 170-184. doi: $10.1509 / \mathrm{jmkg} .70 .4 .170$

Rajogopal, P., \& Montgomery, N. V. (2011). I imagine, I experience, I like: The false experience effect. Journal of Consumer Research, 38 , 578-594. doi:10.1086/660165

Scoboria, A., Mazzoni, G., \& Jarry, J. L. (2008). Suggesting childhood food illness results in reduced eating behavior. Acta Psychologica, 128, 304-309. doi:10.1016/j.actpsy.2008.03.002

Scoboria, A., Mazzoni, G., Jarry, J., \& Bernstein, D. M. (2012). Personalized, not general, suggestion affects false memory and suggestion-consistent behavior. Acta Psychologica, 139, 225-232. doi:10.1016/j.actpsy.2011.10.008

Whittlesea, B. W. A. (1993). Illusions of familiarity. Journal of experimental Psychology: Learning, Memory, and Cognition, 19, 12351253. doi:10.1037/0278-7393.19.6.1235 